\title{
Toxicological safety assessment of ZeolFat energy feed additive
}

\author{
Aliya Kashaeva, ${ }^{1, *}$, Shamil Shakirov ${ }^{2}$, Firaya Akhmetzyanova ${ }^{1}$, and Damir Khairullin ${ }^{1}$ \\ ${ }^{1}$ Department of Inspection and Control of Food and Feed, Bauman Kazan State Academy of Veterinary Medicine, 420029, Kazan, \\ Russia \\ ${ }^{2}$ Department of Agrobiological Research, Tatar Research Institute of Agriculture - Subdivision of the Federal Research Center Kazan \\ Scientific Center of RAS, 420059, Kazan, Russia
}

\begin{abstract}
Development of inexpensive and environmentally friendly feed additives based on waste from the food industry and expired products as energy sources for animals is of current relevance and high demand. The study aimed to test the toxicological safety of ZeolFat energy feed additive (EFA) on laboratory animals. The tests on white rats showed that ZeolFat EFA is a low-toxic feed product with no cumulative properties revealed. The animals exhibited satisfactory physical state and a good appetite during experimental feeding. They were active, and their response to external stimuli remained similar to that before EFA introduction. ZeolFat EFA had a stimulating effect on carbohydrate and lipid, and mineral metabolism in rats, thereby ensuring a high increase in their live weight.
\end{abstract}

\section{Introduction}

Numerous domestic and foreign research developments, and experience gained by livestock breederspractitioners show that complete feed of animals, high productive cows in particular [1, 2], is impossible without highly efficient feed additives. The disadvantage of most of the additives is that they lack not only crude protein but also energy $[3,4]$.

Feed additives currently used to solve this problem such as dry palm fats, propylene glycol, glycerin and other regulators of carbohydrate and lipid metabolism are rather expensive [5].

For normal growth, development and productivity, animals need not only proteins, fats and carbohydrates but also minerals. The main part of the feed produced in the Republic of Tatarstan does not satisfy the need of animal for minerals [6]. The deficit of daily consumption of macro- and microelements amounts to 70-80 \%. Therefore, new available and highly effective feed additives are required to replenish not only the part of energy animals lack in their ration but also the mineral dietary component.

In turn, oil and fat production waste can minimize the energy deficit in animal diets. In addition to common wastes (oilcake, meal, etc.), a number of other equally valuable types of secondary raw materials are found in the agro-industrial complex of our region [7,8], which, if not disposed, can cause environmental pollution. This primarily concerns expired food products returned from retail chains, which can become the raw material for production of high-quality feed [9].

In this regard, ZeolFat EFA developed by scientists of the Department of Agrobiological Research, Tatar Research Institute of Agriculture - Subdivision of the
Federal Research Center Kazan Scientific Center of RAS (AAAA-A18-118031390148-1) and the Department of Inspection and Control of Food and Feed, Bauman Kazan State Academy of Veterinary Medicine, is an original feed additive for high productive cows produced according to evidence-based recipe.

ZeolFat EFA consists of expired mayonnaise with a fat mass fraction of 58.0-67.0 \%, natural mineral activated zeolite and a new generation of the Bisphenol5 antioxidant.

A distinctive feature of ZeolFat EFA is that the proposed technological solution uses activated zeolite prepared by drying in a three-circuit drying drum in a specified temperature regime in accordance with $\mathrm{TU}$ 10.91.10-002-27860096-2017. Annealing occurs in a mild mode without destroying the structure of the raw material. As a result, new qualities developed in the product include enhanced absorbent, catalytic and ionexchange properties. Bisphenol-5 antioxidant is added to prevent oxidation (rancidity) of fatty acids and to actively participate in metabolism.

The study aimed to test the toxicological safety properties of ZeolFat EFA on laboratory animals.

\section{Materials and Methods}

The research and laboratory experiment to determine the toxicological safety of the feed product was performed in the educational laboratory for analysis of feed and livestock products, Vivarium of FSBEI HE Bauman Kazan State Academy of Veterinary Medicine, on clinically healthy laboratory animals (white linear rats) with an average body weight of $161.8 \pm 4.4 \mathrm{~g}$.

The animals were kept in standard conditions: the air temperature of $+23{ }^{\circ} \mathrm{C}$, relative humidity of $55 \%$. The

*Corresponding author: aliam_81@mail.ru 
rats were kept in cages with free access to water, and sawdust was used as litter. Granular PK 120-4 complete feed was the basic feed for all animals.

The acute toxicity of ZeolFat EFA was assessed in accordance with GOST R ISO 10993-11-2009 by single introduction of EFA into the organism of rats on an empty stomach [10,11].

For the experiment, four groups of animals (one control and three experimental groups) of both sexes, ten animals each, were formed by the group-analog method.

Distilled water was intragastrically administered to the animals of the control group using the probe, and various doses of ZeolFat EFA (4000, 6000 and 8000 $\mathrm{mg} / \mathrm{kg}$ of body weight) were administered to the rats of experimental groups I, II, II and III, respectively. The volume of the injected fluid did not exceed $4 \mathrm{ml}$.

The reaction to the test feed additive was monitored immediately after its use and during the next 14 days. The criteria to assess acute toxicity were feed intake, the clinical picture of intoxication, the number of died animals, the time of their death, and diagnostic autopsy of individual animals [12].

The experimental part performed to determine the cumulative properties of ZeolFat EFA was evaluated by the subchronic toxicity test in accordance with Lim R. et al. [13]

The cumulative properties were determined by repeated intragastric administration of aqueous suspensions of the test additives to 20 white linear rats. For the research and laboratory experiment, two groups of animals were formed - control and experimental ones.

Observation of the animals was performed for 24 days from the moment the test feed additives were introduced into the animal organism. The clinical picture, poisoning probability, general state, behavior, nutritional excitability, the integrity of the hair-coat covering and other signs were analyzed.

The cumulation coefficient was calculated by the formula proposed by Yu.S. Kagan and V.V. Stankevich (1964) [14, 15].

The chronic toxicity of ZeolFat EFA was studied in accordance with GOST R ISO 10993-11-2009 [16].

For the experiment, forty 2-month white linear rats were chosen. Four groups, one control and three experimental, 10 rats each, were formed using the pairanalog method.

The experiment included two stages: preparatory (10 days) and record (30 days). The preparatory stage implied observation of the health state, nutritional activity, when the rats of the experimental groups were adjusted to new food. At the record stage, the rats of the control group received complete feed (PK 120-4). Different doses of ZeolFat EFA $(1.5,2.5$, and $3.5 \%$, respectively) were introduced instead of a similar amount of PC 120-4. EFA had been mixed with complete feed daily for 30 days.

During experimental feeding, clinical and physiological state of the rats, safety of the livestock and feed intake were recorded daily, and control weighing of the animals was performed after 1, 15 and 30 days.

At the end of the record stage, three animals from each group were decapitated under mild ether anesthesia for pathomorphological studies and analysis of the hematological parameters of blood serum.

Blood was tested at the medical advisory center of FSBEI HE Kazan State Academy of Veterinary Medicine and Vettest Veterinary Laboratory (Kazan).

Statistical processing of the data was performed using Microsoft Excel. The validity of intergroup differences was determined using Student's criterion.

\section{Results and Discussion}

Table 1 shows the results of obtained for the acute toxicity of ZeolFat EFA.

Table 1. Acute toxicity of Zeolfat EFA tested on white rats $(\mathrm{n}=10)$

\begin{tabular}{|c|c|c|c|c|}
\hline Group & \multirow{2}{*}{$\begin{array}{c}\text { EFA } \\
\text { dose, } \\
\text { mg/kg }\end{array}$} & \multicolumn{3}{|c|}{$\begin{array}{c}\text { Experimental results, number } \\
\text { of animals }\end{array}$} \\
\cline { 3 - 5 } & & fell ill & died & survived \\
\hline Control & - & 0 & 0 & 10 \\
\hline Experimental, I & 4000 & 0 & 0 & 10 \\
\hline Experimental, II & 6000 & 0 & 0 & 10 \\
\hline Experimental, III & 8000 & 0 & 0 & 10 \\
\hline
\end{tabular}

A single oral administration of the test EFA doses did not cause death of laboratory animals during the entire observation period.

The state of the experimental rats after 14 days remained satisfactory; the animals demonstrated a good appetite. They were active, and their respond to external stimuli remained similar to that before the use of EFA.

No distortion of the functional activity of the digestive and urinary systems and other toxic pathologies could be observed [17].

The pathological autopsy of the decapitated laboratory animals showed that the heart, lungs, spleen and stomach of the animals were within the physiological norm, no visible pathological changes in these organs were found. Organs and tissues of the animals from the experimental groups did not visually differ from the control by morphological indicators.

In this experiment, we could not use generally accepted mathematical processing of the obtained data proposed by G.N. Pershin, since no dead animals were found in all the studied groups during the experimental period (14 days). In this regard, the semi-lethal dose $\left(\mathrm{LD}_{50}\right)$ was not determined.

Thus, ZeolFat EFA belongs to hazard class IV (GOST 12.1.007.76).

The cumulative effect was evaluated by repeated intragastric administration of aqueous suspensions of ZeolFat EFA to 20 white linear rats for 24 days. Aqueous suspension was introduced through an atraumatic probe in the following doses: the first 4 days - $800 \mathrm{mg} / \mathrm{kg}$ of body weight (1/10 of the maximum tolerated dose of $\mathrm{LD}_{50}$ ), then the dose was increased 1.5-fold every 4 days. By the end of the experiment, the daily dose was $6075 \mathrm{mg} / \mathrm{kg}$ of body weight (Table 2).

The results of the study of cumulative properties from 1 to 4 days and from 5 to 8 days of the experiment, with repeated intragastric administration of aqueous suspension 
of ZeolFat EFA 800 and $1200 \mathrm{mg} / \mathrm{kg}$ of body weight showed the occurrence of a pain shock, the signs of which disappeared within 10-15 minutes after the experiment.

Table 2. Cumulative properties of ZeolFat EFA, $n=10$

\begin{tabular}{|c|c|c|c|c|}
\hline \multirow{2}{*}{$\begin{array}{c}\text { Experim } \\
\text { ental } \\
\text { days }\end{array}$} & \multicolumn{4}{|c|}{ Indicator } \\
\hline & $\begin{array}{l}\text { Daily } \\
\text { dose, } \\
\mathrm{mg} / \mathrm{kg}\end{array}$ & $\begin{array}{c}\text { Total dose } \\
\text { per } 4 \text { days, } \\
\mathrm{mg} / \mathrm{kg}\end{array}$ & $\begin{array}{l}\text { Total dose by } \\
\text { administration } \\
\text { periods, } \mathrm{mg} / \mathrm{kg}\end{array}$ & $\begin{array}{c}\text { Mortality, } \\
\text { number of } \\
\text { animals }\end{array}$ \\
\hline $1-4$ & 800 & 3200 & 3200 & 0 \\
\hline $5-8$ & 1200 & 4800 & 8000 & 0 \\
\hline $9-12$ & 1800 & 7200 & 15200 & 0 \\
\hline $13-16$ & 2700 & 10800 & 26000 & 0 \\
\hline $17-20$ & 4050 & 16200 & 42200 & 0 \\
\hline $21-24$ & 6075 & 24300 & 66500 & 0 \\
\hline
\end{tabular}

The effect of aqueous suspension of the test feed additive introduced daily at a dose of $1800 \mathrm{mg} / \mathrm{kg}$ was manifested on day 9. From that day, the animals showed decreased activity, lack of appetite, loss of mobility, as well as general lethargy, which lasted on average up to 2 hours. After that, the vital functions of the laboratory animals were observed to restore.

At daily doses increased to 2700 and $4050 \mathrm{mg} / \mathrm{kg}$, similar symptoms occurred on days 13-16 and 17-20 and remained up to 3.5-4.0 hours.

After daily introduction of the test feed additive in a daily dose of $6075 \mathrm{mg} / \mathrm{kg}$ of body weight, on day 21 the rats exhibited decreased activity, loss of mobility and other symptoms. At the same time, the rats showed interest in food and water, but the time of intoxication increased up to 5.5 hours, with full recovery after 12 hours after introduction of the feed additive. No died animals in this group were found, which indicates that the test feed additive does not have a detrimental effect on the organism.

When determining the cumulative properties of the ZeolFat EFA with regard to the absence of died laboratory animals and the indicator of the average lethal dose, the cumulation coefficient was calculated as the ratio of the total dose with repeated administration of the additive to the additive dose with a single administration.

The cumulation coefficient during intragastric administration was equal to 8.31 [14].

Thus, it can be concluded that the maximum physiologically applicable dose of ZeolFat EFA for laboratory animals is $6075 \mathrm{mg} / \mathrm{kg}$ of body weight. According to the hygienic classification (Medved L.I. et al. 1964), the test feed additive belongs to substances with weakly expressed cumulation.

The feed additives are used in animal diets to improve feed characteristics. In this regard, it is necessary to determine the dose of the feed additive that can maximally satisfy the needs of the animal organism and do not have negative effects [18].

The study of chronic toxicity showed that in the experimental groups, as well as in the control, the number of animals did not change after the experiment. The experimental animals, satisfactorily tolerated the test feed additive, without any visible pathology. Throughout the experiment, there were no changes in behavior, intake of food and water. The experimental animals of all groups were mobile, the hair-coat covering remained smooth with a characteristic shine [19].

An important indicator showing the growth and development of animals is the change in body weight. The use of ZeolFat EFA as part of PK 120-4 had a positive effect on the growth rate of the rats (Table 3 ).

Table 3. Change in body weight of laboratory animals, $g$

\begin{tabular}{|l|c|c|c|c|}
\hline \multirow{2}{*}{\multicolumn{1}{|c|}{ Indicator }} & \multicolumn{4}{c|}{ Group $(\mathrm{n}=10)$} \\
\cline { 2 - 5 } & Control & Experimental, I & Experimental, II & Experimental, III \\
\hline Body weight on the 1st day & $161.33 \pm 0.88$ & $161.67 \pm 0.62$ & $161.33 \pm 0.43$ & $161.33 \pm 0.67$ \\
\hline After 15 days & $193.00 \pm 1.15$ & $196.00 \pm 1.08^{*}$ & $200.00 \pm 0.93^{* * *}$ & $214.67 \pm 1.03^{* * *}$ \\
\hline After 30 days & $203.33 \pm 0.33$ & $209.00 \pm 0.58^{* * * *}$ & $215.33 \pm 0.43^{* * *}$ & $221.00 \pm 0.58^{* * *}$ \\
\hline Absolute gain, g & $42.00 \pm 2.30$ & $47.33 \pm 3.20$ & $54.00 \pm 2.60^{* * *}$ & $59.67 \pm 1.88^{* * * *}$ \\
\hline Relative gain, \% & 100.00 & 102.79 & 105.90 & 108.69 \\
\hline Average daily gain, g & 1.40 & 1.58 & 1.80 & 1.99 \\
\hline Relative to the control, in \% & 100.00 & 112.86 & 128.57 & 142.14 \\
\hline
\end{tabular}

Note: ${ }^{*} \mathrm{P} \leq 0.05 ;{ }^{* *} \mathrm{P} \leq 0.005 ;{ }^{* * *} \mathrm{P} \leq 0.001$

During the period of experimental feeding (30 days), the body weight of the laboratory animals in the control group increased by $42.00 \mathrm{~g}$, and that in the experimental groups I, II, and III by $47.33 ; 54.00$ and $59.67 \mathrm{~g}$ $(\mathrm{P} \leq 0.001)$ or $2.79 ; 5.90$ and $8.69 \%$, respectively.

Introduction of EFA in the feed mixture did not show adverse effect on the change in the average daily gain of laboratory animals. On the contrary, rats of experimental groups I, II and III exceeded the animals of the control group in average daily gain by $12.86 \%, 28.57$, and $42.14 \%$, respectively.

The experiment showed that prolonged consumption of ZeolFat EFA by the experimental animals does not lead to changes in the state of the skin and hair, as well as in visible mucous membranes.
The amount of feed and water consumed by the rats of the experimental group did not differ from that consumed by the animals of the control group. Animals of all groups were active, the behavior of the experimental rats did not differ from the control and corresponded to this animal species, physiological functions were normal. During the experiment, the death of animals, both in the experimental and in the control groups, was not observed [20].

To control the physiological state of experimental laboratory animals, the morphological and biochemical composition of the blood was studied. The results of the studies of the biochemical composition showed that all indicators were within the physiological norms (Fig. 1). 


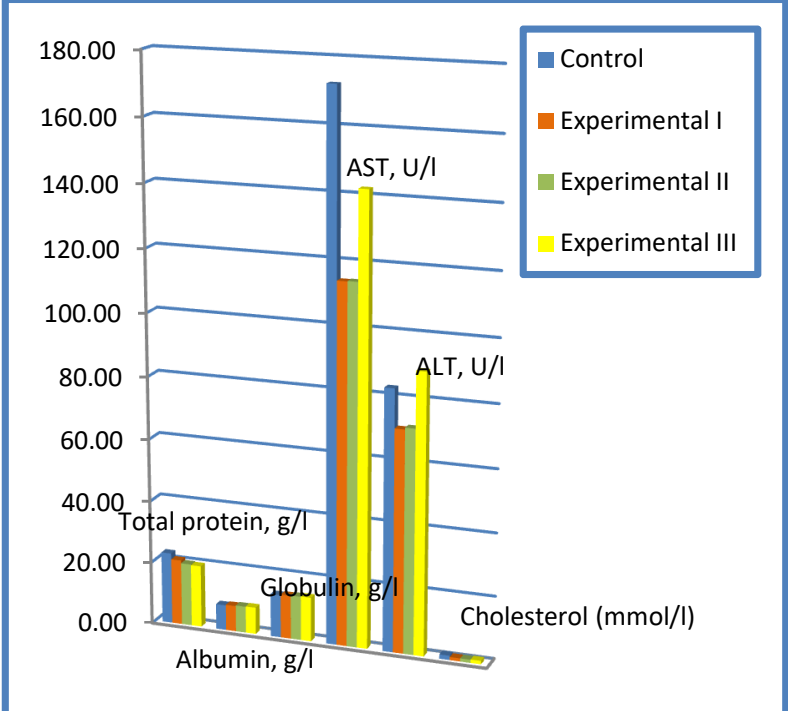

Fig. 1. Biochemical parameters of blood serum of laboratory animals

It should be noted that the concentration of total protein in the blood serum of the animals of the experimental groups was higher than that of the control group by $6.2 ; 14.7$ and $14.9 \%$, albumin - by $4.2 ; 6.4$ and $10.5 \%$, respectively. Concentration of AST, on the contrary, tended to decrease in the groups by $33.7 ; 33.6$ and $17.5 \%$ with respect to the control. In experimental groups I and II, there was a decrease in ALT indicator from 83.20 to $71.50 \mathrm{U} / 1$.

It is known that the blood cholesterol level shows the intensity of fat metabolism in the body (T.E. Tkachenko, 2003). The serum cholesterol content of the rats of the control group was 1.39 , in the experimental group it attained 1.00 ..1.10 mmol/l.

Morphological blood parameters were within the norm (Fig. 2).

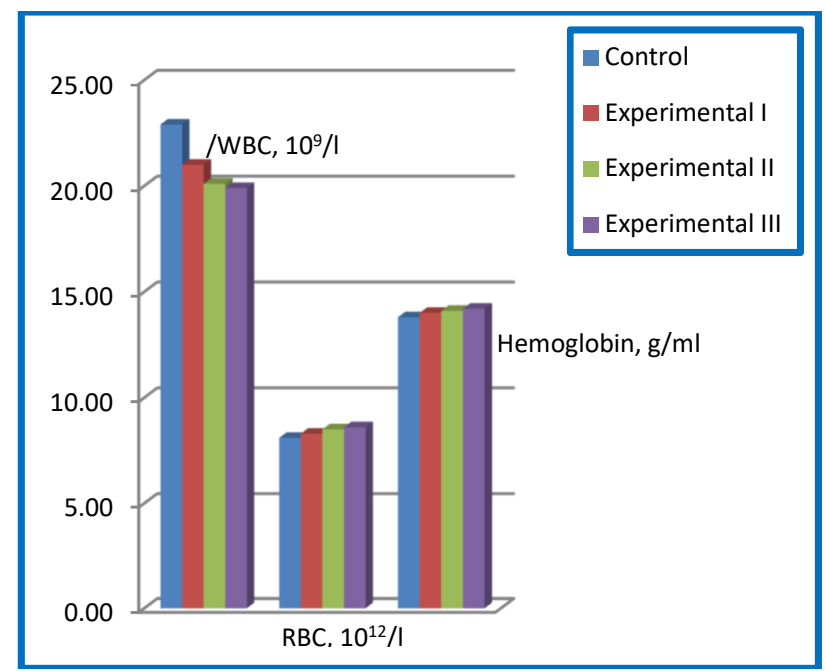

Fig. 2. Hematological blood parameters of laboratory animals

It should be noted that in the blood of the rats from experimental groups I, II and III there was a slight decrease in leukocytes (by $8.3 \%, 12.2$, and $13.1 \%$, respectively). The average volume of red blood cells and the hemoglobin content in erythrocyte were observed to increase, which indicates a stimulating effect on the blood.

The level of total calcium in the blood serum tended to increase, which directly depends on the dose of the feed additive introduced into the diet of animals. Thus, an increase in the calcium level of the animals of group I was $7.3 \%$, and that of the animals of experimental groups II and III was 14.1 and $7.7 \%$, respectively.

The content of inorganic phosphorus in the laboratory animals from experimental groups I and II was 1.42 and $12.38 \%$ higher than that in the control animals, and in the animals from group III it was $2.38 \%$ lower than that in the animals of the control group.

Thus, introduction of ZeolFat EFA into the feed of laboratory animals shows positive dynamics in biochemical parameters of blood serum that characterize carbohydrate-lipid and mineral metabolism, which is economically feasible.

\section{Conclusion}

The study showed that ZeolFat EFA is a low-toxic nutritious feed, which does not have cumulative properties. With respect to the main parameters of the hazard classification, the test feed additive belongs to non-toxic compounds, and to hazard class IV according to GOST 12.1.007.76.

The state of the laboratory animals during the experimental feeding remained satisfactory, they showed a good appetite. The animals were mobile, the reaction to external stimuli remained similar to that before the use of the feed additive. No pathological changes in the organs and tissues of laboratory animals were found.

The experiment performed to determine chronic toxicity of the additive showed that the use of EFA provided significant gain in body weight and had a stimulating effect on metabolism. In addition, the additive positively affected the biochemical parameters of blood serum that characterize the carbohydrate-lipid and mineral metabolism.

\section{References}

1. H.A. Amerkhanov, Dairy and beef cattle breed., 1, 2-5 (2017)

2. M.R. Kudrin, E.M. Kislyakova. Proc. of Kazan State Acad. of Veter. Med. named after N.E. Bauman, 223, 96-101 (2015)

3. O.A. Artemyeva, O.V. Pavlyuchenkova, E.N. Kotkovskaya et al., Dairy and beef cattle breed., 6, 33-35 (2015)

4. G.A. Broderick, Animal, 12(8), 1722-1734 (2018)

5. Sh.K. Shakirov, M.Sh. Tagirov et al., Feed product., 9, 39-42 (2011)

6. L.P. Zaripova et al., The feed of the Republic of Tatarstan: composition, nutritional value and use (Foliant, Kazan, 2010) 272 p.

7. S.K. Mustafayev, E.O. Smychagin, Proc. of KubSTU, 3, 883-895 (2019) 
8. G.A. Yarmots, A.B. Satkeeva, L.P. Yarmots, Farm animal feed. and feed product., 4, 16-25 (2016)

9. A.R. Kashaeva, F.K. Akhmetzyanova, Sh.K. Shakirov, I.N. Kamaldinov, Proc. of Kazan State Acad. of Veter. Med. named after N.E. Bauman, 241, 104-107 (2020)

10. R.R. Akhmedzhanov, S.I. Kudinova, Fundamentals of toxicology, textbook (TPU, 2003) 84 p.

11. E.P. Dolgov, E.V. Kuzminova, E.V. Tyapkina, Proc. of Krasnodar Sci. Center for Zootech. and Veter. Med., 249-253 (2018)

12. S.T. Minzanova, V.A. Milyukov, A.V. Krayushkina, D.M. Arkhipova et al., Toxicol. Reports, 5, 457-467 (2018)

13. R. Lim, K. Rink, H. Glass et al., Arch. Int. Parmacodyn., 130, 335-336 (1961)

14. Yu.S. Kagan, V.V. Stankevich, Proceedings: Actual issues of occupational health, industrial toxicology and occupational pathology in the oil and petrochemical industries, 48-49 (1964)
15. A.G. Koshchaev, E.I. Migina, Yu.A. Lysenko, Veter. Med. of the Kuban, 4, 14-15 (2014)

16. GOST R ISO 10993-11-2009. Medical Products. Assessment of the biological effects of medical devices. Part 11. Studies of general toxic effects. Introduction. 2009-10-20 (Standartinform, Moscow, 2010), $36 \mathrm{p}$.

17. M.A. Bagmanov, Sh.K. Shakirov, R.N. Fayzrakhmanov, Proc. of Kazan State Acad. named after N.E. Bauman, 208, 256-261 (2011)

18. R.N. Fayzrakhmanov, Metabolism, productivity and quality of animal products when using sapropelbased feed additives in their diets, doct. dissertation (2018) 348 p.

19. V.O Ezhkov, A.Kh. Yapparov, A.M. Ezhkova, I.A. Yapparov et al., Nanotechnol Russ., 11, 497 (2016)

20. E.I. Semenov, S.Y. Smolentsev, N.N. Mishina, S.A. Tanaseva, et al., Indian Veter. J., 95(6), 16-19 (2018) 